technique; and modern techniques using the gamma-camera, ${ }^{99} \mathrm{mTc}-\mathrm{MAA}$, and oblique views $^{3}$ would be expected to give greater reproducibility.

Surely, given these data, the statement that the lung scans "correlated poorly with the results of pulmonary angiography" should be reversed to say that the interpretation of pulmonary angiograms even by experts was, to say the least, difficult and correlated poorly with the findings of perfusion lung scanning.

ANDREW HILSON

J G AYRES

Nuclear Medicine Department, Guy's Hospital,
London SE1 9RT

1 Bell, W R, and Simon, T L, American Heart fournal, 1976, 92, 700.

Tow, D E, and Simon, A L, Progress in Cardiovascular Disease, 1975, 27, 239.

Nielson, P E, Kirchner, P T, and Gerber, F H,
fournal of Nuclear Medicine, 1977, 18, 967 .

SIR,-Contrary to the conclusion reached by Professor J R A Mitchell (9 June, p 1523), on pharmacological grounds, I firmly believe that fatal pulmonary embolism can be preventedperhaps not always but certainly in the great majority of cases. I cannot speak for modern orthopaedic prosthetic procedures of which I have no experience.

In 1926, because of the appalling incidence of death from embolism, I most seriously considered and discussed abandoning surgery in favour of some other discipline. I believe that the Fowler position, combined with really good, careful nursing (as then understood), contributed to the tragedies that occurred so frequently. This it did by creating a quiet pool of blood in the veins of the pelvis and the lower limbs and so encouraging the free clotting of blood. With renewed activity the clot was swept into the heart and the pulmonary artery with fatal results. Then I had an idea: literally to stand Fowler on his head. One pillow, nine-inch blocks at the foot of the bed, active leg exercises, and deep breathing were the order of the day-supported by dedicated sisters and nurses and assisted by enthusiastic physiotherapists. The previously ever-present fear of fatal pulmonary embolism ended.

In 1946, two things coincided. Firstly, on becoming head of the department of surgery at Liverpool I was transferred to the Royal Infirmary (because it was in a ring fence with the university) from the Royal Southern Hospital, thus being separated from the team with which I had worked. Secondly, early ambulation, better described as getting-out-ofbed-and-sitting-in-a-chair, was becoming the "in thing." We fell for it, and pulmonary embolism returned as surely as night follows day. Reinstitution of the nine-inch blocks and the rest of the old discipline put us back in the clear. This and a judicious compromise with early ambulation ensured a speedy convalescence and a near guarantee of safe recovery. Fatal postoperative pulmonary embolism can be prevented-not, perhaps, pharmacologically but physiologically.

Charles Wells

Hoylake,
Wirral, Merseyside L47 1HB

SIR,-I would like to take issue with Professor J R A Mitchell's review (9 June, p 1523) on the prevention of pulmonary embolus, because almost all of my patients receive subcutaneous heparin before and after major general surgery. Had the article been entitled "Surgical mortality" I might not have commented, for indeed a $1 \%$ reduction in overall mortality, though encouraging and representing a large number of lives saved, cannot be regarded as statistically significant. But Professor Mitchell quotes the figures obtained from a multicentre trial which investigated the value of subcutaneous heparin prophylaxis. He recalls that in the test group there were two deaths from pulmonary embolus, compared with 18 in the control group. This is a most impressive result which confirms the original findings of Sharnoff and mirrors my own experience precisely, since in the last five years only one of my general surgical patients has had this complication found at necropsy.

Not only did Professor Mitchell bury the first vital point in the overall result, but he omitted something else. Had the use of subcutaneous heparin had lethal complications, the overall death rates in the control and test groups of the multicentre trial would have been closer than the difference in deaths from pulmonary embolus alone: on the contrary, the difference was $25 \%$ greater. This finding, though scientifically not significant, does support Sharnoff's view that all cardiovascular complications of surgery are reduced by subcutaneous heparin. In my own practice, I have encouraged my surgical colleagues to accept subcutaneous heparin prophylaxis for patients with an old history of coronary artery disease or untreated hypertension: in the last seven years 35 such patients whom I have been able to follow up carefully have revealed only one who developed transient central chest pain after surgery and his electrocardiogram showed no change, while a further 50 such patients have survived surgery and so far as I know did not suffer further infarction in the perioperative period

I feel very strongly that Professor Mitchell's article has blurred the already complex issue of surgical pulmonary embolus. Surely the use of subcutaneous heparin prophylaxis in general surgical patients does prevent the majority of pulmonary emboli, even if it does not prevent other lethal complications of surgery.

R H FELL

Wexham Park Hospital

Slough, Berks SL2 4HL

\section{Malaria prophylaxis}

SIR,-Following the correspondence initiated by Dr Eric Walker (16 December, p 1718) and the article by Dr C J Ellis and others (10 February, p 385), we have reviewed our records for incidence of the diagnosis of malaria during the past 24 months in the pathology department at Redhill General Hospital. This hospital serves a large urban and semirural area, including Gatwick Airport and a small immigrant community at Crawley.

From June 1977 to June 1978, 21 cases of malaria were diagnosed, six of these being in patients of Caucasian origin. From June 1978 to June 1979 the total number was 18 , of whom eight were Caucasian. Out of this total of 39 patients, only 13 had attempted any form of prophylaxis. In one of these it was inadequate, and in two others (members of air crew) prophylaxis had only been intermittent. Where patients were asked if prophylaxis had been continued following arrival in this country, it was apparent that the need for continuation of treatment had not been fully appreciated. In the one death which occurred from cerebral complications of Plasmodium falciparum, no antimalarials had been taken by the victim, an Irish schoolgirl holidaying with her parents in Zambia. It was believed by her parents that prophylaxis was not necessary in the urban area where they lived.

While we have not experienced an increase in incidence in our own area, it is apparent that the majority of patients who contract malaria are either ignorant or heedless of the necessity for prolonged antimalarial prophylaxis. This seems to underline the necessity for increased dissemination of information to travellers regarding prophylaxis.

\section{H E MunRo-FAure} D DONALDSON

Department of Pathology, Redhill General Hospital,

\section{Rubella vaccination}

SIR,-Dr Philip Hopkins questions (23 June, $p$ 1712) the rationale of the UK policy of vaccination of schoolgirls aged $11-14$ and the current DHSS campaign to increase uptake in this age group.

The answers to his specific queries are: (1) Rubella vaccine is very effective, with seroconversion rates of $95-98 \% \%^{1}$ (2) The duration of immunity after vaccination cannot yet be fully assessed as the vaccination programme has been running for only nine years. However, antibody levels persist for periods of six years or more. ${ }^{2}$ It could be that a booster dose will ultimately be found to be necessary to cover women until the end of their childbearing years.

The impact of the schoolgirl vaccination programme on the incidence of congenital rubella will not become apparent until the mid-1980s, as most of those vaccinated have not yet reached the peak fertility age group (25-29). There has, however, been recent evidence that the proportion of seronegative women has been reduced by the programme. ${ }^{3}$

The effectiveness of the programme depends on a high vaccine uptake. Half the schoolgirls being vaccinated already have naturally acquired immunity. The other half must be vaccinated before they enter their childbearing years. Vaccination at the age of 11-14 is done without prior serological testing and is free from the problem of ensuring adequate contraception for three months, simpl fying the procedure considerably.

The reason for screening older women for rubella immunity at present is to identify those (approximately 15\%) who are seronegative and to offer them vaccine. This is an interim measure to reduce the incidence of congenital rubella until the schoolgirl programme makes its full impact.

Dr Hopkins's proposed policy of concentrating solely on women who are planning a family comes at too late a stage for sound preventive medicine. Many first pregnancies are unplanned. Few couples who do plan would remember to attend three months before trying for a pregnancy, despite publicity for the service.

I trust that Dr Hopkins realises that the approaches in his practice to a minority group of women consulting him for contraceptive advice is not a comprehensive enough way to reduce the incidence of congenital rubella. In six months Gringras 4 reached fewer than a 